\title{
ANÁLISE DE PARÂMETROS DE FIXAÇÃO BIOLÓGICA DE NITROGÊNIO EM CULTIVARES COMERCIAIS DE SOJA
}

\author{
TOLLER, Eduardo Volpe ${ }^{1}$ \\ BÁRBARO, Ivana Marino ${ }^{2}$ \\ BÁRBARO-JUNIOR, Laerte Souza ${ }^{3}$
}

Recebido em: 2008-08-18

Aprovado em: 2009-03-24

ISSUE DOI: $10.3738 / 1982.2278 .135$

\begin{abstract}
RESUMO: Objetivou-se analisar parâmetros de fixação biológica do nitrogênio em cultivares de soja em resposta à inoculação e aplicação de cobalto e molibdênio via pulverização foliar. O delineamento foi em blocos ao acaso, com testemunhas adicionais com três repetições, consistindo de 18 tratamentos: 15 cultivares tratadas e mais três cultivares eleitas entre as 15 e utilizadas como testemunhas (não tratadas). No estádio V6 avaliaram-se em 5 plantas ao acaso por parcela útil os parâmetros: número de nódulos (NNOD), massa seca de nódulos (MNOD), da raiz (MRAIZ) e parte aérea (MFOL). Os dados obtidos foram submetidos à análise de variância pelo teste $\mathrm{F}$ e às médias comparadas pelo teste de Scott Knott $(\mathrm{p} \leq 0,05)$. Pelos resultados obtidos foram verificadas que as cultivares diferiram entre si quanto aos parâmetros de fixação biológica do nitrogênio. Os maiores valores de NNOD e MNOD foram obtidos nas cultivares IAC 23 e M-SOY 5942. Para a MRAIZ destacaram-se as cultivares BRS 133 e BRS 184, e para MFOL a BRS 184. Em relação às estimativas de correlações os melhores resultados foram obtidos para NNOD x MNOD e MRAIZ x MFOL.
\end{abstract}

Palavras-Chave: Simbiose. Nodulação. Variedades. Glycine max.

\section{ANALYSIS OF PARAMETERS OF BIOLOGICAL NITROGEN FIXATION IN SOYBEAN COMMERCIAL CULTIVARS}

SUMMARY: It was objectified to analyze parameters of biological nitrogen fixation in soybean cultivars in response to the inoculation and foliar application of cobalt and molybdenum. The experimental design was the complete randomized block with additional checks, with three replications, consisting of 18 treatments: 15 soybean cultivars treated and more three cultivars chosen among the 15 cultivars and used as checks (not treated). In the stadium $\mathrm{V}_{6}$ were evaluated in 5 plants to the for useful portion the parameters: number of nodules

(NNOD), the nodules dry weight (WNOD), the root (WROOT) and the shoots (WSHO). The obtained data were submitted the variance analysis by the test $\mathrm{F}$ and the averages compared by Scott Knott's test $(\mathrm{p} \leq 0,05)$. For the obtained results were verified that the soybean cultivars differed to each other with relationship to the parameters of biological nitrogen fixation. The largest values of NNOD and WNOD were obtained in cultivars IAC 23 and M-SOY 5942. For WROOT they stood out you cultivars them BRS 133 and BRS 184 and for WSHO BRS 184. In relationship the estimates of correlations the best results were obtained for NNOD x WNOD and WROOT x WSHO.

Keywords: Symbiosis. Nodulation. Varieties. Glycine max.

\footnotetext{
1 Estudante de Agronomia da Faculdade de Agronomia Doutor Francisco Maeda. Área Produção Vegetal

2 Pesquisadora Dra. da Agencia Paulista de Tecnologia dos Agronegócios, Secretaria de Agricultura e Desenvolvimento - Pólo Regional Alta Mogiana, Colina-SP. Doutora em Genética e Melhoramento de Plantas pela FCAV/UNESP, campus de Jaboticabal-SP.

3 Graduando em Agronomia da Faculdade de Agronomia Doutor Francisco Maeda, Ituverava-SP
} 


\section{INTRODUÇÃO}

As principais fontes de nitrogênio disponíveis para a soja são os adubos nitrogenados e a fixação biológica de nitrogênio (FBN). No Brasil, a FBN representa a fonte economicamente e ecologicamente mais viável para a cultura. A simbiose, que ocorre entre esta leguminosa e as bactérias do gênero Bradyrhizobium resulta na formação de nódulos nas raízes da planta, possibilitando a obtenção de todo o nitrogênio que a cultura necessita, mesmo com expectativa de alta produtividade de grãos (EMBRAPA, 2005; ZILLI et al., 2006).

Os solos brasileiros não possuem, naturalmente, as bactérias responsáveis pela nodulação e fixação do nitrogênio eficientemente em soja, sendo, portanto, indispensável a utilização de inoculante no tratamento das sementes. Merecem também uma atenção especial os micronutrientes cobalto e molibdênio, que participam diretamente no processo de fixação biológica (ZILLI et al., 2006).

No Brasil, estudos pioneiros citam diferenças entre cultivares de soja quanto ao potencial de nodulação e outros parâmetros de FBN (DÖBEREINER; ARRUDA, 1967; BROSE et al., 1979; VARGAS et al., 1982), entretanto, são poucos os trabalhos que vêm sendo conduzidos, atualmente, com a finalidade de avaliar a variação entre genótipos de soja brasileiros quanto à eficiência do processo. Particularmente na última década, os caracteres de FBN não vêm sendo contemplados diretamente nos programas de melhoramento genético da soja, que tem priorizado características relacionadas com a produção e a resistência a doenças. O relato da lacuna provocada por uma descontínua avaliação destas características, como fator responsável por perdas genéticas de até 30\% na contribuição de nitrogênio para as plantas, foram observados em várias cultivares atualmente disponíveis no mercado quando comparadas com os parentais que as originaram (BOHRER; HUNGRIA, 1998; HUNGRIA; BOHRER, 2000).

Para conseguir manter o esforço da pesquisa brasileira, que posicionou o Brasil, atualmente, como o país com maior contribuição do processo biológico para a cultura, o presente trabalho objetivou verificar diferenças na capacidade de fixação biológica de nitrogênio em cultivares de soja, através da avaliação de parâmetros relacionados à FBN, quando na presença de tratamento envolvendo a inoculação associada à aplicação de cobalto e molibdênio via pulverização foliar. 


\section{MATERIAL E MÉTODO}

O ensaio foi instalado no ano agrícola 2007/08, em área de reforma de pastagem (Latossolo Vermelho Escuro - fase arenosa) pertencente à sede do Pólo Regional de Desenvolvimento Tecnológico dos Agronegócios da Alta Mogiana, situada em Colina, SP.

O solo foi preparado de maneira convencional. Posteriormente, a área foi sulcada e adubada. A adubação da área foi feita com base na interpretação dos resultados da análise química do solo (Quadro 1), distribuindo-se no sulco de semeadura a quantidade equivalente de $350 \mathrm{~kg} / \mathrm{ha}$ da fórmula 0-20-20.

QUADRO 1: Relatório de análise de solo referente a área onde foi conduzido o ensaio. Colina, SP. Ano Agrícola 2007/08.

\begin{tabular}{|c|c|c|c|c|c|c|c|c|c|c|c|c|}
\hline $\mathbf{P}$ & $\mathbf{M . O}$. & $\mathbf{p H}$ & $\mathbf{K}$ & $\mathbf{C a}$ & $\mathbf{M g}$ & $\mathbf{H}+\mathbf{A l}$ & $\mathbf{S i}$ & $\mathbf{S}$ & $\mathbf{A l}$ & $\mathbf{S B}$ & $\mathbf{T}$ & $\mathbf{V}$ \\
\hline $\mathrm{mg} / \mathrm{dm}^{3}$ & $\mathrm{~g} / \mathrm{dm}^{3}$ & $\mathrm{CaCl} 2$ & \multicolumn{2}{|c|}{$---\mathrm{mmolc}^{2} \mathrm{dm}^{3}-----$} & $\mathrm{mg} / \mathrm{Kg}$ & $\mathrm{mg} / \mathrm{dm}^{3}$ & $----\mathrm{mmolc} / \mathrm{dm}^{3}-$ & $\%$ \\
\hline 6 & 16 & 4,9 & 1,7 & 14 & 7 & 25 & ----- & ---- & -- & 22,7 & 47,7 & 48 \\
\hline
\end{tabular}

Utilizou-se o delineamento experimental de blocos ao acaso com três repetições, composto por 15 cultivares de soja na presença do tratamento: inoculação associada a aplicação de cobalto + molibdênio via pulverização foliar. Foram escolhidas três cultivares (IAC 23, BRS 184 e Embrapa 48) que foram utilizadas também como testemunhas (ausência de tratamento) para comparação. Cada parcela constituiu-se de quatro linhas de 5 metros de comprimento, espaçadas de $0,5 \mathrm{~m}$, considerando-se como área útil apenas as duas linhas centrais.

Para o tratamento das sementes, utilizou-se um inoculante comercial turfoso que contêm as estirpes Semia 5079 e Semia 5019, atualmente recomendadas, na dose de 200 $\mathrm{g} / 50 \mathrm{~kg}$ de sementes. No estádio fenológico $\mathrm{V}_{5}$, as parcelas foram pulverizadas via foliar com uma formulação comercial contendo $1,5 \%$ de cobalto e $15 \%$ de molibdênio na dose de $100 \mathrm{ml} / \mathrm{ha}$. Além disso, as sementes foram tratadas com o fungicida comercial Vitavax + Thiran 200 SC, visando controle de fungos patogênicos do solo, sendo o inoculante aplicado por último, no dia da semeadura. Adotaram-se também alguns cuidados para garantir uma maior eficiência do inoculante, como a inoculação realizada à sombra e distribuição uniforme do inoculante em todas as sementes.

Todas as técnicas de cultivo da soja, como escolha de cultivares, época de semeadura, população de plantas, controle de plantas daninhas, insetos e doenças seguiram as recomendações técnicas para a cultura da soja da Embrapa (2005). 
Foram coletadas cinco plantas ao acaso por parcela útil, no estádio fenológico $\mathrm{V}_{6}$ para avaliação dos seguintes parâmetros diretamente relacionados com a FBN: nodulação: os resultados foram apresentados quanto ao número (nódulos/planta) (NNOD) e massa seca de nódulos (g/planta) (MNOD), sendo sua massa determinada através da secagem em estufa com ventilação forçada a $65^{\circ} \mathrm{C}$ por 48 horas, até atingir massa constante; sistema radicular: os resultados foram apresentados quanto à massa seca de raiz (g/planta) (MRAIZ), sendo sua massa também determinada através da secagem em estufa com ventilação forçada a $65^{\circ} \mathrm{C}$ por 48 horas, até atingir massa constante e parte aérea: para a separação da parte aérea foi usado o ponto de inserção cotiledonar como ponto de corte e os resultados foram apresentados para massa seca da parte aérea (g/planta) (MFOL), sendo sua massa seca determinada após secagem em estufa com ventilação forçada a $80^{\circ} \mathrm{C}$ por 72 horas, até atingir massa constante.

Os dados obtidos foram submetidos à análise de variância pelo teste $\mathrm{F}$, e as médias comparadas pelo teste de Scott Knott a $5 \%$ de significância, através do programa computacional Genes (CRUZ, 2001).

\section{RESULTADOS E DISCUSSÃO}

Na Tabela 1, nota-se que as testemunhas (IAC 23, BRS 184 e Embrapa 48) não tratadas com inoculante e produto comercial a base de cobalto e molibdênio produziram menos nódulos e massa seca nodular quando comparadas com as mesmas cultivares na presença do tratamento. No caso das cultivares IAC 23 e Embrapa 48, o tratamento proporcionou cerca do dobro e triplo do NNOD, evidenciando resposta positiva a inoculação. Geralmente há resposta à inoculação das sementes somente em áreas novas ao cultivo de soja, pois, em solos cultivados anteriormente, a população de rizóbio já estabelecida é altamente competitiva por sítios de infecção (JOHNSON; MEANS, 1960).

O maior NNOD foi obtido nas cultivares IAC 23 e M-SOY 5942, com respectivamente, 66,1 e 64,9 nódulos/planta. Por outro lado, apresentaram pior desempenho quanto a nodulação as cultivares transgênicas BRS 245RR, BRS 244RR e CD 213RR que não diferiram entre si pelo teste de Scott Knott a 5\%, com, respectivamente, 22,6, 22,3 e 18,4 nódulos/planta. Esses resultados concordam com os relatos de Vargas; Hungria (1997) de que com cerca de 10 aos 15 dias após a emergência, a avaliação inicial da nodulação pode ser um bom indicativo da eficiência da fixação biológica do nitrogênio. Nessa fase, a soja deve apresentar de 4 a 8 
nódulos/planta. Já, nos estádios do florescimento $\left(\mathrm{R}_{1}\right.$ e $\left.\mathrm{R}_{2}\right)$, plantas bem noduladas devem apresentar de 15 a 30 nódulos por sistema radicular.

TABELA 1: Avaliação da nodulação (número e massa seca nodular) e da produção da matéria seca da parte aérea e raiz em cultivares de soja em resposta à inoculação e pulverização foliar com cobalto e molibdênio, safra 2007/08. Colina-SP.

\begin{tabular}{|c|c|c|c|c|}
\hline Cultivares & $\begin{array}{l}\text { NNOD }^{1} \\
\text { /planta }\end{array}$ & $\begin{array}{l}\text { MNOD }^{1} \\
\text { g/planta }\end{array}$ & $\begin{array}{l}\text { MRAIZ }^{1} \\
\text { g/planta }\end{array}$ & $\begin{array}{l}\text { MFOL }^{1} \\
\text { g/planta }\end{array}$ \\
\hline NK 7059RR & $47,1 \mathrm{~b}$ & $0,13 b$ & $0,93 \mathrm{c}$ & $4,80 \mathrm{~d}$ \\
\hline M-SOY 5942 & $64,9^{\mathrm{a}}$ & $0,17 \mathrm{a}$ & $1,33 b$ & $6,87 \mathrm{c}$ \\
\hline IAC 23 & $66,1^{\mathrm{a}}$ & $0,19 \mathrm{a}$ & $1,27 b$ & $7,20 \mathrm{c}$ \\
\hline BRS 133 & $28,1 \mathrm{c}$ & $0,08 \mathrm{~d}$ & $1,53 \mathrm{a}$ & $9,80 \mathrm{~b}$ \\
\hline M-SOY 7210 & $28,5 \mathrm{c}$ & $0,09 \mathrm{c}$ & $1,27 \mathrm{~b}$ & $8,07 \mathrm{c}$ \\
\hline BRS 184 & $34,2 \mathrm{c}$ & $0,11 b$ & $1,80 \mathrm{a}$ & $11,93 \mathrm{a}$ \\
\hline CD 214RR & $31,3 \mathrm{c}$ & $0,09 \mathrm{c}$ & $1,13 \mathrm{c}$ & $7,73 c$ \\
\hline Embrapa 48 & $31,4 \mathrm{c}$ & $0,07 \mathrm{~d}$ & $0,80 \mathrm{~d}$ & $4,93 \mathrm{~d}$ \\
\hline CD 225RR & $31,4 \mathrm{c}$ & $0,12 b$ & $1,33 b$ & $7,13 \mathrm{c}$ \\
\hline BRS 245RR & $22,6 \mathrm{~d}$ & $0,07 d$ & $0,67 d$ & $3,27 \mathrm{e}$ \\
\hline BRS 244RR & $22,3 d$ & $0,06 \mathrm{~d}$ & $1,40 \mathrm{~b}$ & $6,33 c$ \\
\hline CD 219 RR & $29,1 \mathrm{c}$ & $0,08 \mathrm{~d}$ & $1,27 b$ & $7,40 \mathrm{c}$ \\
\hline CD 213 RR & $18,4 d$ & $0,07 \mathrm{~d}$ & $0,87 \mathrm{~d}$ & $5,40 \mathrm{~d}$ \\
\hline CD 202 & $51,1 \mathrm{~b}$ & $0,09 \mathrm{c}$ & $1,00 \mathrm{c}$ & $6,80 \mathrm{c}$ \\
\hline M-SOY 8008 & $34,3 \mathrm{c}$ & $0,08 \mathrm{~d}$ & $1,07 \mathrm{c}$ & $6,60 c$ \\
\hline BRS $184^{72-}$ & $30,4 c$ & $0,10 \mathrm{c}$ & $1,27 \mathrm{~b}$ & $10,2 \mathrm{~b}$ \\
\hline IAC $23^{/ 2}$ & $29,9 c$ & $0,12 b$ & $1,60 \mathrm{a}$ & $7,33 \mathrm{c}$ \\
\hline Embrapa $48^{/ 2}$ & $10,1 \mathrm{e}$ & $0,05 \mathrm{~d}$ & $1,07 \mathrm{c}$ & $6,80 \mathrm{c}$ \\
\hline M geral & 33,9 & 0,09 & 1,2 & 7,1 \\
\hline $\mathrm{CV}(\%)$ & 11,3 & 15,9 & 13,3 & 10,1 \\
\hline $\mathrm{F}$ (tratamento) & $43,6^{* *}$ & $17,4 * *$ & $9,9 * *$ & $23,7 * *$ \\
\hline $\mathrm{F}$ (Cultivar) & $43,3 * *$ & $18,9 * *$ & $10,5^{* *}$ & $24,7 * *$ \\
\hline $\mathrm{F}$ (testemunha) & $27,1 * *$ & $14,4 * *$ & $8,6^{* *}$ & $19,2 * *$ \\
\hline $\mathrm{F}(\mathrm{C} \times$ testemunha $)$ & $79,9 * *$ & $2,0^{\mathrm{NS}}$ & $5,3^{*}$ & $19,3 * *$ \\
\hline
\end{tabular}

${ }^{\mathrm{T}}$ Médias seguidas da mesma letra minúscula na coluna não diferem entre si (Scott Knott $\mathrm{p} \leq 0,05) ;{ }^{\prime 2}=$ testemunhas; $* *, *,{ }^{N S}=$ significativo a 1,5 e não significativo pelo teste $\mathrm{F}$.

Resultados semelhantes foram obtidos quanto a MNOD, sendo que as cultivares convencionais IAC 23 e M-SOY 5942 foram as que mais se destacaram. Segundo Câmara (2000), plantas com equivalentes de 0,10 a 0,20 g de nódulos secos por planta no florescimento apresentam condições suficientes para a obtenção de altos teores de nitrogênio fixado e, conseqüentemente, alto rendimento de grãos. Já, dez cultivares mostraram valores médios de MNOD inferiores ao recomendado por este autor, variando de 0,06 a 0,09 g/planta. A massa de nódulos seca, sempre que possível, deve ser determinada, pois proporciona melhor correlação com eficiência de nodulação e produtividade de grãos (CÂMARA, 2000). 
A cultivar BRS 184 mostrou maior produção de massa seca radicular e parte aérea, não diferindo da cultivares BRS 133 e da IAC 23 na ausência do tratamento (testemunha) para MRAIZ. A massa da parte aérea seca é parâmetro imprescindível de ser avaliado, uma vez que apresenta alta correlação com o $\mathrm{N}$ total acumulado pelas plantas $(\mathrm{r}=0,87 * *$ e $\mathrm{r}=0,92 * *)$ dispensando a análise do mesmo (BOHRER; HUNGRIA (1998) e HUNGRIA; BOHRER (2000).

Na Tabela 2, as melhores estimativas de correlações foram obtidas para NNOD $x$ MNOD e MRAIZ x MFOL por apresentaram valores significativos a $5 \%$ de probabilidade, positivos e com elevadas magnitudes (acima de 0,89 ).

Para NNOD x MNOD observa-se que quanto mais nódulos a planta de soja apresentar maior será sua massa seca nodular, estando de acordo com os resultados obtidos por Bárbaro et al. 2006, que verificaram correlação significativa, elevada e positiva $\left(r=0,9892^{* *}\right)$ entre estes parâmetros. Câmara (2000) ressaltou que a massa seca de nódulos proporciona melhor

TABELA 2: Estimativa dos coeficientes de correlação simples entre parâmetros de FBN, 2007/08.

\begin{tabular}{lc}
\hline Variáveis & Correlação \\
\hline NNOD x MNOD & $0,8857^{*}$ \\
NNOD x MRAIZ & $0,1189^{\mathrm{NS}}$ \\
NNOD x MFOL & $0,0622^{\mathrm{NS}}$ \\
MNOD x MRAIZ & $0,2769^{\mathrm{NS}}$ \\
MNOD x MFOL & $0,1728^{\mathrm{NS}}$ \\
MRAIZ x MFOL & $0,9057^{*}$ \\
\hline * Significativo a 5\% de probabilidade, pelo teste t.
\end{tabular}

correlação com eficiência de nodulação e produtividade. Porém, no campo, isso nem sempre é possível, cabendo ao técnico ou ao produtor, bom senso na observação dos aspectos morfológicos externos e internos dos nódulos como: boa nodulação e eficiência de fixação biológica de nitrogênio tem sido associada à presença de nódulos com 3 a $8 \mathrm{~mm}$ de tamanho e com superfície rugosa e internamente, coloração rósea a avermelhada, indicando atividade da leghemoglobina.

Ainda em relação à Tabela 2, observa-se que quanto maior a produção de massa seca radicular maior a produção da massa seca da parte aérea, discordando dos resultados obtidos por Bárbaro et al. (2006), que verificaram na estimativa de correlação entre MRAIZ e MFOL que a mesma foi negativa, de magnitude baixa e não significativa pelo teste $\mathrm{t}(\mathrm{r}=-0,0979)$. 
As demais estimativas de correlação simples (NNOD x MRAIZ, NNOD x MFOL, MNOD x MRAIZ e MNOD x MFOL) foram não significativas.

\section{CONCLUSÃO}

As cultivares diferenciam-se quanto aos parâmetros número de nódulos por planta, massa seca nodular, da raiz e parte aérea;

As cultivares que mais se destacaram foram M-SOY 5942 e IAC 23 quanto ao número e massa seca de nódulos, BRS 133 quanto a massa seca radicular e BRS 184 em relação a massa seca radicular e parte aérea;

As melhores estimativas de correlações foram obtidas para número de nódulos com massa seca nodular e massa seca radicular com massa seca da parte aérea.

\section{REFERÊNCIAS}

BÁRBARO, I. M. et al. Avaliação de soja (Glycine max) cultivar IAC-23 quanto a eficiência na fixação biológica de nitrogênio, em área de reforma de pastagem em Colina-SP. Unimar Ciências, v. 15, n.1-2, p. 63-70, 2006.

BOHRER, T. R. J.; HUNGRIA, M. Avaliação de cultivares de soja quanto à fixação biológica do nitrogênio. Pesquisa Agropecuária Brasileira, v.33, p.937-953, 1998.

BROSE, E.; FREIRE, J. R .J.; MULLER, L. Relações entre genótipos de soja (Glycine $\max$ [L.] Merrill), fixação simbiótica do nitrogênio e rendimento de grãos. Agronomia Sulriograndense, v. 15, p. 179-198, 1979.

CÂMARA, G. .M. S. Nitrogênio e produtividade da soja. In: Câmara GMS (Eds.) Soja: Tecnologia da Produção II. Piracicaba, ESALQ/USP. p. 295-339, 2000.

CRUZ, C. D. Programa Genes: Versão Windows: aplicativo computacional em genética e estatística. Viçosa: UFV, 2001. 648p.

DÖBEREINER, J.; ARRUDA, N. B. Interrelações entre variedades e nutrição na nodulação e simbiose da soja. Pesquisa Agropecuária Brasileira, v. 2, p. 475-487, 1967.

EMBRAPA Tecnologia de produção de soja: região central do Brasil. Londrina: Embrapa Soja: Embrapa Cerrados: Embrapa Agropecuária Oeste: Fundação Meridional, 2005. 239p. 
HUNGRIA, M.; BOHER, T. R. J. Variability of nodulation and dinitrogen fixation capacity among soybean cultivars. Biology and Fertility of Soils, v.31, p.45-52, 2000.

HUNGRIA, M.; CAMPO, R. J.; MENDES, I. C. Aspectos básicos e aplicados da fixação biológica do nitrogênio. In: CONGRESSO BRASILEIRO DE SOJA E MERCOSOJA, 2. Foz do Iguaçu. Anais..., EMBRAPA/SOJA. p. 258-267, 2002.

JOHNSON, H. W.; MEANS, U. M. Interaction between genotypes of soybeans and genotypes of nodulating bacteria. Agronomy Journal, v. 52, p. 651-654, 1960.

VARGAS, M. A. T.; PERES, J. R. R.; SUHET, A. R. Fixação de nitrogênio atmosférico pela soja em solos de cerrado. Informe Agropecuário, v. 8, p. 20-23, 1982.

VARGAS, M. A. T.; M. HUNGRIA. Biologia dos solos dos cerrados. EmbrapaCPAC, Planaltina, DF. 1997.524 p.

ZILLI, J. E. et al. Avaliação da fixação biológica de nitrogênio na soja em áreas de primeiro cultivo no cerrado de Roraima. EMBRAPA RORAIMA. 9p. 2006. (Comunicado Técnico, 20). 